\title{
Management of complexity in the care ecosystem
}

\begin{abstract}
Purpose - Managing complexity within care ecosystems is an increasing universal challenge. In health this is emphasised by recent calls for greater care integration to achieve service improvement as levels of comorbidity and frailty grow within populations. This research takes a service dominant logic (SDL) stance in examining the sources, types and nature of complexity within a care ecosystem in the UK
\end{abstract}

Design/Methodology/approach - This illustrative case research focuses on a community care ecosystem. A multi-method approach is employed combining semi-structured interviews, descriptive statistics and secondary data. The results were independently assessed and validated by participants through a second interview phase.

Findings - The findings from this research provide empirical support for the six complexities discussed in the supply chain literature. Identifying these complexities proffers the opportunity of applying manufacturing derived complexity management strategies in care ecosystems. The conceptual model for institutional complexity, derived from the illustrative case study, showed that care professionals face additional complexity challenges in operating care ecosystems.

Practical Implications - The management of complexity in care ecosystems requires professionals to be considerate of institutional arrangements when addressing the consequences of increasing levels of complexity. This necessitates the development of a balanced approach between reducing complexity while absorbing institutional arrangements which minimise risk.

Originality/value - Drawing on the supply chain complexity literature, the paper has developed a framework which guides care professionals facing increasing levels of complexity within the context of their institutional arrangements. As such, this research furthers our understanding of supply chain complexity effects in care ecosystems and provides a platform for future research.

Keywords: Complexity, Healthcare Management, Care Ecosystems, Community

Paper Type Research paper 


\subsection{Introduction}

Complexity and its role in supply chain management is a growing area of research that is providing insights into the sources, types and responses to complexity for manufacturers (Turner et al, 2018; Aitken et al, 2016; Bode and Wagner, 2015). The importance of understanding complexity is also increasing in the care ecosystem as rising levels of comorbidities and fragmentation of services impact on the ability of professionals to deliver quality services (Aronsson et al., 2011). However, there is limited research within public services to guide and support managers on identifying and managing complexities (Churruca et al, 2019; Greenhalgh and Papoutsi, 2018). This paper, through the lens of Service Dominant Logic (SDL), asks 'How does complexity manifest itself as experienced by care ecosystem professionals?' and 'What insights, if any, from supply chain management complexity research can support care ecosystem professionals in improving their services?'

Previous studies on healthcare systems have focused on general or specialist hospitals, but with the growing need to innovate and integrate community hospitals with care in the community a wider scope is needed (Pitchforth et al, 2017; Heaney et al, 2006). Nationally and internationally it is acknowledged that service delivery varies across these types of service supply arrangements. What unites such care ecosystems is the desire to explore integration of nodes (i.e. acute hospitals, community hospitals and homes) and innovate as a strategic means to improve service delivery and outcomes for service users (Pitchforth et al, 2017). To support this strategic desire, we have focused on such an ecosystem to further develop our understanding of complexity and how it is managed. The care ecosystem in this study represents a self-contained network of organisations/departments which integrate specialised competences to provide complex services that deliver a value proposition for patients (Vargo and Lusch, 2017; Frow et al., 2014; Randall et al., 2010; Carroll et al., 2007).

The concept of complexity within healthcare was formally recognized by the U.K. Medical Research Council (MRC) on the production of guidance notes to develop and evaluate complex interventions in 2000. However, this original document, and its subsequent revision in 2008, was criticised for largely avoiding the specific question of what constitutes complexity in care ecosystems. MRC's position altered in 2015 with a movement towards a complex systems perspective however, the sector is still tied to a linear, cause-effect approach to investigating and managing complexity (Greenhalgh and Papoutsi, 2018). The gap between principles and practice in healthcare has led to a "preponderance of broad conceptual discussions, rather than practical or methods articles of how to apply complexity science in healthcare" (Churruca et al, 2019:6). Researchers have recommended that further studies be undertaken to identify ways to reduce complexity and develop approaches to accommodate complexity when implementing change in healthcare (Greenhalgh et al, 2018). The contribution of this paper is to address the lack of clarity on operationalising complexity and how it can be managed in practice. We address the challenge that complexity is an abstract concept with limited relevance and fit for what care professionals need (Greenhalgh et al, 2018; Cohn et al, 2013). Through our research we identify the complexities faced by care professionals as well as approaches to reducing the negative consequences of increasing levels of complexity.

Historically, managing complexity in healthcare was through reducing phenomena to constituent variables. This approach, however, ignores the interactions which are 
emergent and contingent upon one another as well as those aspects which remain uncertain at a local as well as systems level (Nilsson and Darley, 2006). To embrace the universal drive for integrated health and social care systems there is an opportunity of envisaging complexity at a system level, across multiple organisations, which will also require social care service professionals to evolve their comprehension and management of complexity (Sturmberg et al, 2014). Supply chain research provides a platform from which to develop an understanding of complexity. Supply chain management scholars have begun to research a dualistic approach to managing complexity. This envisages complexity in terms of properties, which can be reduced or accommodated to either minimise dysfunctional or embrace strategically important characteristics (Turner et al, 2018; Aitken et al, 2016). From these studies frameworks for identifying and managing complexity within organisations and across boundaries have been proposed (Mazzocato et al, 2014; Manju and Sahin, 2011). Each framework focusing on different dimensions of complexity derived from studies of individual organisations and their perceptions of supply chain partners (Turner et al, 2018; Aitken et al, 2016; Bozarth et al, 2009).

Supply chain concepts from manufacturing into care ecosystems have been highlighted as problematic due to "contradictory, regulatory or commissioning priorities" (Radnor et al, 2012:365). Several researchers have argued that SDL proffers the opportunity to improve public sector services (Osborne et al, 2016; Radnor et al, 2014; Vargo and Lusch, 2008) through focusing on increasing value from a holistic perspective by illustrating "how actors and resources are integrated into a service system" (Westrup, 2018:36). SDL emphasises that activities in the system are "driven by specialised knowledge and services, rather than units of output, at the centre of the exchange process" (Osborne et al, 2013:140). Knowledge is a corner stone of care ecosystems (Williams, 2017). Through applying an SDL lens in conjunction with a synthesis of supply chain derived complexity literature, our research investigates how complexity manifests itself as experienced by care ecosystems professionals and assesses what insights, if any, from the supply chain complexity literature can support professionals in improving their service. The case study examines the services provided by actors and their organisations in a care ecosystem.

\subsection{Literature}

\section{Complexity in Care Ecosystems}

The term care ecosystem is used (Huijsman et al, 2004) to describe a chain of activities performed by multiple organisations (the infrastructure through which product or service passes). Ecosystems refer to groups of organisations that provide complementary services and have significant interdependence on the creation and provision of value (Jacobides et al, 2016). Within service research, scholars have devoted growing attention to complexity and its related issues due to the undoubtedly complex nature of service ecosystems (Gummesson et al, 2019). For example, care ecosystems are represented by a complex community of actors including managers, clinicians, nurses, social workers, specialists, commissioners and regulators to name but a few (Dessers and Mohr, 2019). Through assembling and coordinating specific resources these dynamic ecosystem actors interact and co-create value through the exchange of services to ensure that the needs of patients are addressed (Vargo and Lusch, 2017). Similarly, a patient care pathway can be defined as the entire or part journey a patient might experience when diagnosed with a health condition, for example from pre-diagnosis which might involve seeking assistance from a GP, through to diagnosis, to post-diagnosis including care management in either the 
acute or community hospital setting dependent on need (Williams, 2017). We propose that a care ecosystem provides the infrastructure through which a patient care pathway flows.

Within the care ecosystem hospitals usually operate autonomously due to specialisation (Meijboom et al. 2011). While there are standard patient treatments which translate into physical flows though the ecosystem there is increasing complexity in the form of unique services for patients, specific to clinical need which are embedded as options within patient care pathways. Due to budgetary and resource limitations healthcare capacity, unlike commercial organisations, is not demand-led instead it is "resource-driven" leading to queues and an increased likelihood of service failure (Walley, 2013:887). The degree of complexity of the care process influences the ability of the system to match specialisation with capacity and demand (Mazzocatto et al, 2014).

Against the background of a resource-driven stance healthcare is experiencing greater complexity in patient illnesses and treatment processes along with fragmented vertical integration across the organisation (Aronsson et al, 2011; Gehmlich, 2008). Addressing complexity through a reductionist approach has been the historical modus operandi of care professionals. Segmenting the patients' illnesses into singular components has aligned with a resource-driven perspective which schedules capacity through availability and priorities. The sector has recognised patient treatment is more complex than isolating and treating specific components of an illness rather they are "increasingly being forced to evaluate components across a range of different specialities - bio-medical, organisational, psychological and social - all at work simultaneously" (Cohn et al, 2013:40). Several authors have explored the multidimensional aspects of care and indicated the value of understanding patient needs, even for common conditions such as respiratory diseases and aging, as complex phenomena which require a system approach to deliver value (Orton et al, 2019; Greenhalgh and Papoutsi, 2018; Strange, 2009).

The integrated nature of healthcare systems develops complexity due to the "recursive and dynamic connections between population health, health policy and health care" (Curtis and Riva, 2010:52). Complexity in these integrated systems is reflected in the multitude of relationships between independent and interdependent organisations that interact to deliver patient treatment (Dessers and Mohr, 2018). Attempts to bring coherence to fragmented care systems have been fraught with problems due the high levels of unpredictability in their processes leading to significant levels of complexity (Grudniewicz et al, 2018). Integration of care systems adds another layer of complexity to examining how it manifests itself and the response of managers.

Recognizing the complex nature of illnesses and providing a service which delivers value has broadened the "understanding of patients' healthcare needs and made it possible to describe system constraints and unintended consequences of system interventions on meeting those needs" (Stumburg et al, 2014:73). The dynamic nature of complexity and its potential sources reflect the involvement of multiple healthcare providers in the delivery of care through the ecosystem. Gehmlich (2008) argues that complexity of the care ecosystem could benefit from the application of supply chain management principles and research which the next section examines.

\section{Complexity in Supply Chains}

Studies investigating supply chain complexity have adopted either a system-level perspective (Choi and Krause, 2006) or have taken an organisational level focusing on how complexity manifests itself within the organisation and across its interfaces (Aitken 
et al, 2016). The first approach is reflected in the research deploying Complex Adaptive Systems (CAS). CAS has validity at a high level of abstraction providing an overview of the entire system. Within the supply chain literature Choi et al. (2001:352) state that a CAS "emerges over time into a coherent form, and adapts and organizes itself without any singular entity deliberately managing and controlling it". From a systems level perspective, the primary focus has been to understand how the multitude of organizations that form a supply chain respond as an entity to emerging, intrinsic and extrinsic complexities (Turner et al, 2018). Tukamuhabwa, et al's (2015) literature review on supply chain resilience deployed CAS as a lens to highlight the constant pressures managers experience to adapt their supply networks in dynamic situations. Recently, Schiffling et al (2020) examined humanitarian logistics (HL) in Haiti and Pakistan, through a CAS lens, identifying some common complexity themes and behaviours across organisational boundaries. This approach has also been found to have benefits in situations such as healthcare where "researchers have begun to indicate the value of understanding the behaviours of many common conditions as complex phenomena" (Sturmberg et al, 2014:73). CAS has also been applied in the development of competence and capabilities through, supporting people in recognising the learning opportunities that exist when facing messy and complex problems (Fraser and Greenhalgh, 2001). However, in healthcare the theory has become a source of "fruitful metaphors" (Paley, 2010:61) which fail to provide explanations. Greenhalgh (2009) suggests that CAS is a general world view at a high level of abstraction which needs to be refined and adapted to become more relevant to healthcare professionals. One of the principle challenges of CAS is the lack of definitions of what the theory is or how it should be conceptualised or operationalised (Schiffling et al, 2020; Thompson et al, 2016, Wallis, 2008; Pathak et al, 2007). Gerschberger et al, (2012, p. 1018) also highlight this CAS issue, stating it is problematic "to identify adequate methods for system representation, to investigate interdependencies between core elements, and the specification of adequate complexity parameters that also respect complexity emerging from the external environment." With these limitation CAS has been found to be problematic as a lens to examine specific elements or characteristics of complexity in supply chains.

Over the last 30 years supply chain complexity researchers have sought to define complexity in systems (Turner et al, 2018; Wilding, 1998). Through examining complexity within organisations and across their interfaces academics have revealed the type, source, and nature of supply chain complexity (Aitken et al, 2016; Serdarsan, 2012; Bozarth et al, 2009). Investigating complexity at the organisational level supports research that addresses Gerschberger et al's (2012) CAS challenge of identifying "complexity parameters that also respects complexity emerging from the external environment This level of analysis provides a basis for developing frameworks that assists researchers and healthcare professionalss in identifying and managing internally and externally generated complexity (Turner et al, 2018; Aitken et al, 2016). It is this view of complexity that will be the focus of our explanatory research in the care ecosystem.

Supply chain researchers have strived to develop better insights and comprehension of complexity and provide a portfolio of potential responses (Serdarasan 2012; Bozarth et al, 2009; Childerhouse and Towill, 2004). The early work into supply chain complexity focused on developing an understanding of the nature of complexity, built upon systems complexity literature, in terms of uncertainty in the interaction of system parts and the impact of numerousness. Bozarth et al (2009) examined these complexities within and across manufacturing supply chains identifying and classifying complexity in terms of 
types and sources. The types of uncertainty were labelled as "dynamic" related to uncertainty of interaction outcomes within the supply chain and "detail" highlighting the importance of numerousness to complexity. Sources of complexity were found to derive from "internal" issues or "externally" from up and downstream changes. Complexity has historically been viewed as "dysfunctional" having a deleterious impact on the performance of the supply chain (Bozarth et al., 2009; Vachon and Klassen, 2002). However, researchers have recently begun to recognise that certain levels of complexity may be "necessary" or indeed could be advantageous (Turner et al, 2018; Aitken et al, 2016). These three themes are important in developing an understanding and management of supply chain complexity (Turner et al, 2018; Serdarasan 2012; Bozarth et al, 2009, Wilding, 1998) and are discussed in more detail as follows;

Detail vs dynamic complexity: The themes of detail and dynamic complexity have been paired from the earliest operations and supply chains research into the subject matter. The impact of volume and uncertainty within operations was investigated by Frizelle and Woodcock (1995). Three years later Wilding incorporated deterministic chaos into his supply chain complexity triangle to explain the generation of uncertainty within supply chains. Vachon and Klassen (2002) linked numerousness and uncertainty in their definition of supply chain complexity; Bozarth et al (2009) investigated detail and dynamic complexity across manufacturing supply chains; and recently Aitken et al (2016) deployed the pairing to study approaches to managing complexity. Numerousness and dynamism have been linked across numerous studies due to their prominence in all types of supply chains. Numerousness in a system drives detail complexity. Reflecting the number of customers, suppliers and components that are located within and across boundaries of an organisation (Bozarth et al., 2009). Within a care ecosystem detailed complexity would include patients and their range of illnesses, medical suppliers, multicare agencies and process interactions. This is particularly relevant with increasing levels of patient comorbidity requiring social as well as medical support in their treatment plans. The concept of detail complexity was recognised in 2008 where complex patient interventions consisted of several components. Research into complexity highlighted uncertainty as a major element of dynamic complexity. The interconnected nature of processes and their wider systems can impact performance at other points in unexpected ways (Bode and Wagner, 2015). For example, the bullwhip effect demonstrates how a small change in demand can be magnified across a system leading to significant changes elsewhere in the system. Within the care ecosystem uncertainty can be derived from a multitude of interconnected services and change in one component can provoke unplanned changes throughout the system (Greenhalgh and Papoutsi, 2018; Gummesson et al, 2018; Thompson et al, 2016). For example, cancer care requires customisation through tailoring of services to support individuals however, uncertainty caused by poor information flow can impact treatment plans. Recognition of the interconnectedness of the patient, poor definition of health disorders and their treatment to the wider ecosystem was incorporated in to the MRC guidance in 2015.

Internal vs external generated complexity: Supply chain literature has sought to identify where complexity originates from. Internally complexity can be generated by quality issues, failures to conform to standards, diverse IT systems, poor process controls and organisational structures (Serdarasan, 2012; Manju and Sahin, 2011). Within healthcare these issues are also apparent and challenge care professionals in delivery of a quality service (Liberati et al, 2016). The fragmented nature of care ecosystems and the poor levels of coordination between functional and specialist silos creates internal complexity 
(Westrup, 2018). Rising levels of complex illnesses are also challenging care professionals in the integration of resources across internal departments. External issues across organisational boundaries such as customer demand variances or unclear specification of requirements generate external complexity (Bozarth et al., 2009). The N.H.S. in the U.K. generally operates a fixed capacity model for primary healthcare which results in variation of waiting times as external demand changes (Walley, 2013). Changes to the population profile with increased levels of frailty pose additional challenges for care ecosystems.

Necessary vs dysfunctional complexity: Recent literature has highlighted the dichotomous nature of complexity as it can be both a positive force for change as well as negative influence on efficiency and effectiveness (Turner et al, 2018; Aitken et al, 2016). Necessary complexity can reflect a strategic approach of an organisation to increase numerousness of products or processes to improve the service offered to clients. This positive development will require greater integration of resources and exchange of services in the cocreation of value in the care ecosystem. Necessary complexity can lead to higher levels of dysfunctional complexity. For manufacturing a rise in the number of items can lead to improved turnover. However, increases in product types can also lead to loss of productivity due to more frequent changeovers. Within healthcare necessary complexity can be recognised through the provision of higher levels of support, resource integration and exchange of services across several specialist domains rather than discrete silo based actions. This positive and considered increase in the type and level of support can also have negative consequences in terms of the pressure on the system. Care ecosystems have finite capacity which struggle to flex as demand increases (Walley, 2013). Through improvements in care, people are now living longer however, this is leading to a growth in frailty levels and comorbidities. This positive development of extending life, through increasing service offerings, has led to greater challenges for healthcare professionals. With increasing complexity levels of patient illnesses, it is becoming more challenging for healthcare professionals in care ecosystems to identify the appropriate and effective treatment. These issues are leading to longer waiting times and negatively impacting on the effectiveness, efficiency and capacity of the care ecosystem to deliver expected levels of service. The dichotomous nature of complexity is also evident in medical prescriptions. Provision of medicine to treat illness is necessary however, over or inappropriate prescribing can be dysfunctional leading to deprescribing and potential health issues for patients.

Complexity has become an established area for research in supply chain management demonstrating the potential of the derived conceptual frameworks to inform the actions of healthcare professionals as well as future research opportunities. Most complexity research, as discussed above, is based on manufacturing businesses(Turner et al, 2018; Aitken et al, 2016; Pathak et al, 2007). The manufacturing derived approach has also actively been engaged by actors within care ecosystems, by focusing on the delivery of value through items such as medical devices, pharmaceuticals and hospitalisation. The application of manufacturing-based supply chain complexity concepts in healthcare would suggest that they could have relevance. However, these physical components of the care ecosystem are only one aspect of treating patients and do not in themselves deliver the value or the expected outputs (Joiner and Lusch, 2016). Developing a more comprehensive appreciation of how value can be created and delivered, by products and services, can be gained from utilising a Service Dominated Logic (SDL) (Vargo and 
Lusch, 2008). Through the lens of SDL this research will examine complexity, in terms of service and products, within the care ecosystem.

\section{Service Dominated Logic (SDL)}

Researchers have begun to study the different dominant logics that pervade organisations. Historically and with great provenance the product dominated logic has been omnipresent across most organisations. However, this stance has been increasingly challenged as manufacturers begin to recognise that service is becoming equally if not more important than product, leading to concepts such as servitisation attaining greater visibility in the literature. Over the last 15 years an alternative SDL logic has grown in prominence. SDL provides a lens to make sense of complex systems. Although complexity is inherent in the system, SDL can help "unclutter and uncomplicate complex service ecosystems in a way that provides insights regarding the development of better solutions" (Lusch and Vargo, 2014: 203).

SDL has also been deployed previously to investigate and understand the creation and delivery of value within manufacturing environs and service domains (Westrup, 2018; $\mathrm{Ng}$ et al, 2012). SDL is based on a set of five foundational premises (Vargo and Lusch, 2017). Each of these premises is core to understanding how value is cocreated in care ecosystems. The first premise states service, not product, is the basis of exchange. SDL transcends the argument of product versus services by focusing on the processes of serving and value-in-use (Koskela- Huotari, 2016; McColl-Kennedy et al, 2012). Within SDL tangible products or service offerings are no longer viewed as having inherent value, instead, they are part of a service exchange which delivers and co-creates value through value-in-use. For example, medicines provide part of patient treatment plan however, the services of nursing and the skills of surgeons may be required to cure the patient (Joiner and Lusch, 2016). Value is cocreated by multiple actors, is the second premise, where the service user and the service organisation are jointly involved in creating value within the care ecosystem (Joiner and Lusch, 2016; Gummesson et al, 2018). Integration of resources to support value cocreation is the third premise. Integration of the social as well as economic based resources can be deployed in the creation of value. Within healthcare this becomes apparent in the role of patient's family in the recovery process. The fourth premise states that value is realised by the user of the service. Finally, the fifth SDL premise focuses on the role of institutional arrangements in coordinating actors for value cocreation in ecosystems. These "humanly devised rules, norms and beliefs enable and constrain action" (Vargo and Kusch, 2017:49). Randall and Pohlen (2010) highlight that the SDL premises of value-in-use, value co-creation, and integration, make SDL particularly applicable to supply chain research.

SDL provides the perspective which supports service professionals in moving beyond a reductionist internal focus and enhances service through synchronising and integrating resources across the ecosystem (Westrup, 2018). The co-ordination and alignment of actors and resources being achieved through institutions and their institutional arrangements, represented by rules and norms that enable and constrain activities (Vargo and Lusch, 2017), delivering co-creation of value through service-for-service exchanges (Koskela- Huotari and Vargo, 2016; Lusch and Vargo, 2014; Heinonen et al, 2013). The rules and structures that shape the routines of organisational life are necessarily constraining or prescriptive as often these rules are selectively used, manipulated or ignored (Liberati et al, 2016). SDL provides insights into how care professionals can shift their focus from the whole to the parts, and back again by coupling and decoupling 
resources, enabling them to deploy and relocate resources to meet patient needs within a service based ecosystem (Westrup, 2018, Quist and Fransson, 2014). Actors within the care ecosystem integrate their specialised knowledge and competencies to enable service exchange. These activities support value cocreation within the context of shared institutional arrangements and rules. Figure 1 depicts how the actors working together to integrate resources and exchange services, which are enabled and constrained by shared institutional arrangements, co-create value in the care ecosystem.

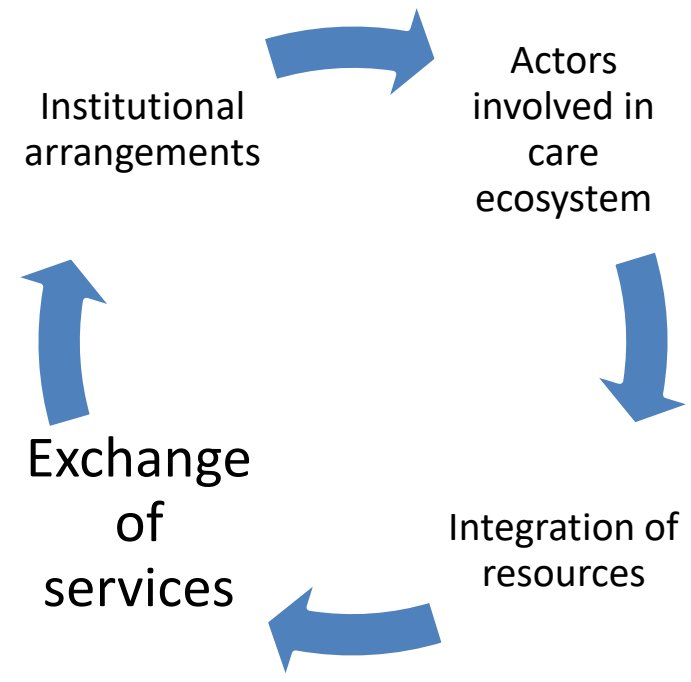

Figure 1: SDL Framework for the Care Ecosystem (adapted from Vargo and Lusch, 2017)

For management research SDL offers a "conceptual frame of reference for understanding and interpreting outcome-based value propositions" (Randall et al. 2010:36) supporting the development of insights and understanding of knowledge intensive service supply chains that collaboratively create value (Vargo and Lusch, 2017; Lusch, 2011; Lambert et al, 2006). With SDL providing a coherent narrative describing how, through the integration of resources and service exchange, actors operating within an ecosystem, defined by shared institutional arrangements, can cocreate value (Vargo and Lusch, 2017). Few studies have examined the intersection between SDL and service supply chains (Vural, 2017).

SDL provides researchers with a lens to investigate care ecosystems and the complexity that exists therein by studying the service-to-service exchanges and processes which support the co-creation and delivery of value (Joiner and Lusch, 2016). Chakraborty and Dobrykowski (2013) conceptually examine the complexity of a hospital supply chain thorough the SDL lens and call for empirical studies to theorize the linkages. Responding to this request, this study, through SDL and the synthesised literature on supply chain complexity, empirically investigates a care ecosystem to answer the two research questions outlined earlier; 'How does complexity manifest itself as experienced by care ecosystem professionals?' and 'What insights, if any, from supply chain management complexity research can support care ecosystem professionals in improving their services?'

\subsection{Research Methodology}

Data were collected using an instrumental single illustrative case study (Greenhalgh et al, 
2009; Lodge and Banford, 2008). A case study strategy supports embryonic research, where a limited body of evidence exists (Meredith et al. 1998) and within under researched settings (Pitchforth et al, 2017; Heaney et al, 2006) where approaches to testing previous research propositions are not relevant (Eisenhardt, 1989). Our research questions lend themselves to an explanatory approach and an inductive methodology to allow the building of theoretical insights (Yin, 2014; Eistenhardt, 1989). An illustrative case was selected over other case study designs (e.g. exploratory) to serve as a means to improve understanding of complexity within a healthcare setting. We avoid excessive details of the case to retain the illustrative view. As such the case is not suggesting an explanation pertaining to all healthcare ecosystems and builds on the complexity within supply chains as detailed in the literature review.

In contrast to existing literature the illustrative case study does not compare the acute hospital setting with a community hospital but rather addresses the strategic call for care professionals to explore the integration of healthcare services (Pitchforth et al 2017). We have assessed the illustrative care ecosystem with a SDL lens in conjunction with the complexity literature. Figure 2 is an illustration of a typical service supply design for the care ecosystem addressing step up (e.g. stepping up care dependent on severity of condition and/or the number of medical illnesses a patient has or alternative support for someone who is unable to safely remain in their own home, but long-term residential care or a hospital admission is not immediately necessary) and step down (e.g. supportive and rehabilitative care given to a patient recuperating from an illness or intervention, who is regaining independence) for a selection of care pathways (conditions) which flow through an ecosystem. The case study defines the boundaries of the care ecosystem from the point of referral from GP or an acute hospital through to the point arrival at home (or similar setting) with appropriate support to ensure patient safety. While patients receive services as they transition from organisation to organisation and subsequently to their home base (which could include residential homes and nursing homes), care professionals predominantly remain within an organisational boundary.

\section{Care Ecosystem}

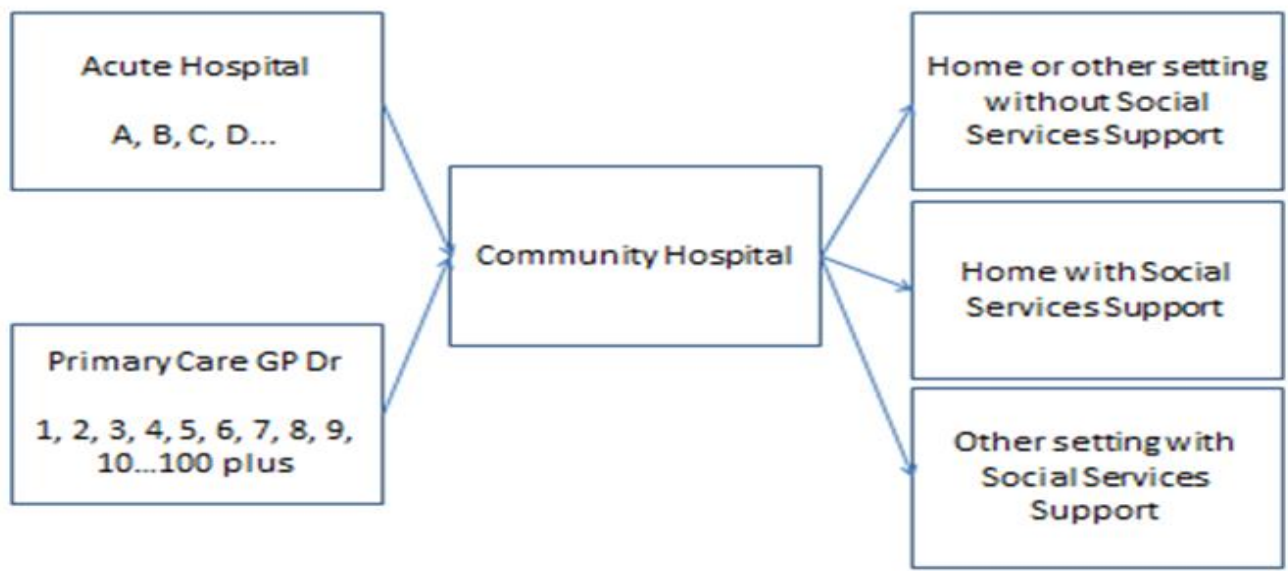

Figure 2: The care ecosystem

The organisations involved in the operation of the overall care ecosystem are GP 
surgeries, Acute Hospitals, Community Hospital, and Local Authority for support services (e.g. funding Social Services and some residential and nursing homes). Those actors involved are clinicians, nursing staff (including discharge planning and liaison), therapists, social workers and managers.

\begin{tabular}{|l|l|l|l|}
\hline & \multicolumn{1}{|c|}{$\begin{array}{c}\text { Acute Hospitals } \\
\text { (AH) }\end{array}$} & $\begin{array}{l}\text { Community Hospital } \\
\text { (CH) }\end{array}$ & $\begin{array}{l}\text { Home care/ } \\
\text { Social Services } \\
\text { (C) }\end{array}$ \\
\hline $\begin{array}{l}\text { Specialty (bio- } \\
\text { medical) (1) }\end{array}$ & $\begin{array}{l}\text { Doctor: (General } \\
\text { Medicine); } \\
\text { Nursing (Surgical); } \\
\text { OT (Surgical Base): }\end{array}$ & $\begin{array}{l}\text { Nursing } \\
\text { (Rehabilitation); } \\
\text { OT(Surgical): } \\
\text { Physiotherapist } \\
\text { (Surgical) }\end{array}$ & $\begin{array}{l}\text { District Nurse: } \\
\text { OT (Local } \\
\text { Authority } \\
\text { Based) }\end{array}$ \\
\hline Social (2) & $\begin{array}{l}\text { Manager (General } \\
\text { Surgery); }\end{array}$ & $\begin{array}{l}\text { Director (Community); } \\
\text { Discharge Planner } \\
\text { (Community Hospital); }\end{array}$ & $\begin{array}{l}\text { Social Services } \\
\text { Manager } \\
\text { Social worker } \\
\text { (Local Authority) }\end{array}$ \\
& Medicine) & Manager (Community \\
& Hospital) & \\
\hline
\end{tabular}

Table 1: Selected Ecosystem Participants with specialty in brackets

Our research questions are concerned with the perspectives of managers and care professionals. The participants were selected to reflect the influencing factors of care complexity (Cohn et al, 2013) and to represent the various professionals of organisations from different parts of the care ecosystem (figure 2), and from different, but relevant, disease condition specialties (bio-medical and social). The participants have been grouped as shown in table 1 to ensure anonymity when discussing findings. The participant coding reflects the organisation using bracketed initials on the horizontal axis followed by the number to reflect the group (in brackets) from which the interview comments were drawn (on the vertical axis of the table) e.g. AH1 represents the interview participants from Acute Hospitals with bio-medical specialties.

The data collection design as shown in table 2 focused predominantly on semi structured interviews augmented with secondary data in the form of:

1. Current care pathways relevant to the ecosystem (secondary data) - e.g. documentation used throughout the process including performance measurements, blank forms/templates, standardized work routines (where appropriate) were also assessed 2. Activity data (quantitative descriptive data) for patient admissions and discharges (anonymised) - which include medical condition, patient age, demand and capacity profile for a 12-month period.

Previous care research, for example Esain (2011) and Lodge and Bamford (2007), have employed similar multiple data collection methods to evaluate innovation and improvement in case study research. 


\begin{tabular}{|l|l|l|}
\hline $\begin{array}{l}\text { Healthcare } \\
\text { specialism }\end{array}$ & $\begin{array}{l}\text { Aspects of Care Professionals' } \\
\text { Understanding }\end{array}$ & Data Source \\
\hline Bio-medical & $\begin{array}{l}\text { Patient care pathways } \\
\text { Clinical need }\end{array}$ & $\begin{array}{l}\text { Secondary data } \\
\text { Interviews }\end{array}$ \\
\hline Organisational & $\begin{array}{r}\text { Ecosystem/supply chain } \\
-\quad \text { Demand and capacity } \\
-\quad \text { Specialities } \\
-\quad \text { Skills }\end{array}$ & $\begin{array}{l}\text { Quantitative data } \\
\text { Empirical } \\
\text { Interviews }\end{array}$ \\
\hline Physiological & Co-morbidities & Secondary data \\
\hline Social & $\begin{array}{l}\text { Understanding of patient's } \\
\text { social need }\end{array}$ & Interviews \\
\hline
\end{tabular}

Table 2: Data collection design and data sources required to address aspects of care professional understanding.

Participants were asked to take part in two rounds of interviews. Questions focused on participants' experiences related to their role, the tasks performed and the range of interactions with actors in the care ecosystem. The first round of interviews were audio recorded, then manually coded and analysed independently by two researchers against definitions of complexity from the literature to understand dynamic situations. The interview questions and coding used are shown in Appendix A. The questions were designed to address the overall research questions (as seen in table 3 ). The outcome of the coding and analysis was then verified by the third author.

\begin{tabular}{|l|l|l|}
\hline Research Questions & $\begin{array}{l}\text { SDL care ecosystem } \\
\text { (Figure 1) }\end{array}$ & $\begin{array}{l}\text { Semi Structured Interviews } \\
\text { (Appendix A: interview } \\
\text { protocol) }\end{array}$ \\
\hline \multirow{4}{*}{$\begin{array}{l}\text { How does complexity } \\
\text { manifest itself as experienced } \\
\text { by care ecosystem } \\
\text { professionals? }\end{array}$} & $\begin{array}{l}\text { Actors involved in the } \\
\text { care ecosystem }\end{array}$ & $\begin{array}{l}\text { Q1/Q3/Q5/Q9 decoded using } \\
\text { 'sources of complexity' }\end{array}$ \\
\cline { 2 - 3 } & Integrations of Resources & $\begin{array}{l}\text { Q2/Q3/Q5/Q9 decoded using } \\
\text { 'sources of complexity' }\end{array}$ \\
\cline { 2 - 3 } & Exchange of Services & $\begin{array}{l}\text { Q3/Q5/Q7/Q9 decoded using } \\
\text { 'sources of complexity' }\end{array}$ \\
\cline { 2 - 3 } & $\begin{array}{l}\text { Institutional } \\
\text { Arrangements }\end{array}$ & $\begin{array}{l}\text { Q5/Q7/Q9 decoded using } \\
\text { 'sources of complexity' }\end{array}$ \\
\hline $\begin{array}{l}\text { What, insights, if any, from } \\
\text { supply chain management } \\
\text { complexity research can } \\
\text { support care ecosystem } \\
\text { professionals in improving } \\
\text { their services? }\end{array}$ & $\begin{array}{l}\text { Feed back into SDL } \\
\text { framework (figure 1) }\end{array}$ & $\begin{array}{l}\text { Q4/Q6/Q8/Q9 sources of } \\
\text { complexity and participants } \\
\text { ideas on improving efficiency } \\
\text { and effectiveness across the } \\
\text { ecosystem. }\end{array}$ \\
\hline
\end{tabular}

Table 3: Interview question design related to research questions

The second interview was designed to further validate coding enabling the original participants to affirm meaning of initial statements recorded. All participants were reinterviewed (with the exception of the doctor), audio recorded by one researcher and then re-coded by the remaining two researchers. In addition, the quantitative data analysis was 
shared with the participants. The protocol was designed to investigate and record the experiences of working within the care ecosystem and supporting the main quest of the study of identifying how complexity manifests itself as portrayed by care professionals.

\subsection{Results}

\section{Complexity Identified}

Our results are presented to firstly help understand the bio-medical, organisational, physiological and social derived complexities in context drawing on the quantitative and secondary data (table 2). Secondly the findings of the interview process are revealed showing social interactions and interpretations related to our research questions. Contributions from participants are illustrated by organisation (e.g. AH = Acute hospital followed by the number to reflect the group (e.g. 1 = Medical group) from which the interview comments were drawn. The descriptive statistics and secondary data provide the context for complexity in our case study. The semi-structured interviews were designed to shine a light on social interpretation of complexity as experienced by care professionals.

\section{Descriptive statistics and secondary data}

In relation to the flow of patients from one organisational setting to another the descriptive statistics showed that for the case study supply chain (figure 2) significantly more inpatients receiving treatment at the community hospital originated from the two main acute hospitals in the region. Nearly three quarters of patients leaving the community hospital, leave to return to their place of residence (figure 3).

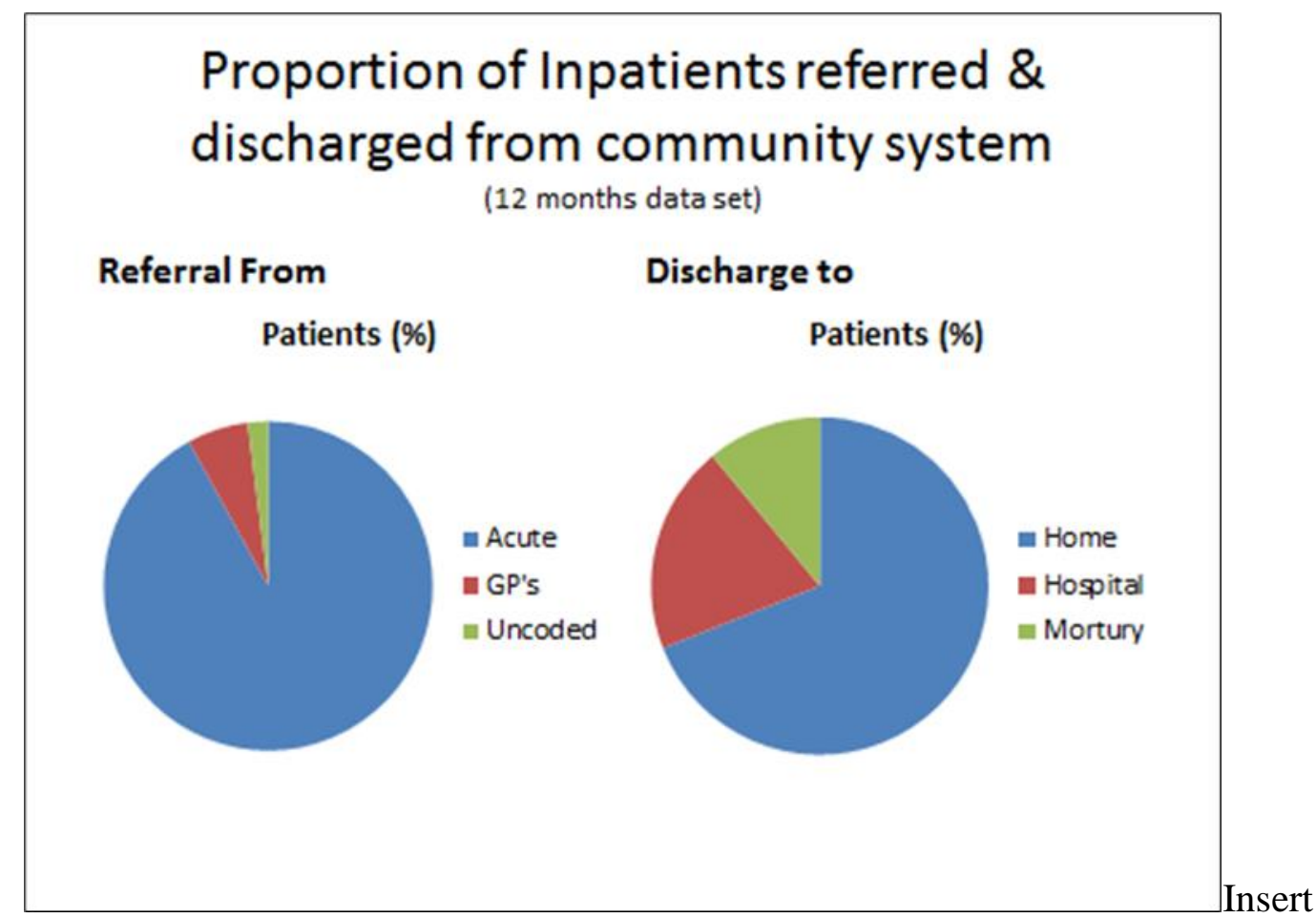

Figure 3: The annual summary of inpatients referred and discharge

Patients who were admitted by GPs to the community hospital were predominantly 
arriving between 12-6pm on weekdays, with admissions from acute hospitals arriving from $3-6 \mathrm{pm}$ in the afternoon on weekdays. As a higher volume of patients arrive at the community hospital from the two largest acute hospitals in the region the time period from 3-6pm and potentially sometime after represented the potential for a time-based bottleneck.

Each department within the community hospital had different institutional arrangements for admission, including focus of treatment (medical specialisation), key performance measures and in some cases different forms of paperwork. The externally generated demand for a condensed admission phase and different institutional arrangements created dynamic complexity and pressure on actors which had the potential of diminishing the quality of service exchange. The period of time which patients stayed for treatment within the community hospital varied. Seven percent of patients left within 5 days of admission, $20 \%$ of patients left within 15 days, $50 \%$ of patients within 40 days, and $80 \%$ of patients within 88 days. The time spent as a patient within the community hospital was not a function of age but rather a combination of factors. An indicator of the factors at play were those patients who were coded as delayed transfers of care, (that is patients deemed medically fit to be discharged but without a safe place to be discharged to). This group included patients from 50 years and upwards. Some patients would be discharged to their own home once modifications were made by social services or others to make the environment safe (e.g. install handrails). Other patients were waiting for a place to become available in a suitable care facility and their needs to be absorbed by the care ecosystem. It was noted that those who were to reside in care homes after discharge often had their rooms taken when being admitted for inpatient treatments at acute hospitals (AH1/AH2).

Within the community hospital there were patients waiting for x-rays (up to 4 days) and computed tomography scans (up to 4 weeks) to aid decision making about treatment and recovery progress. Once the requirement for an occupational therapist (OT) was confirmed the lead-time for an OT assessment was 7-10 days. The service exchange process was not integrated to support value co-creation in a timely manner requiring the care ecosystem to absorb the variations. Different institutional arrangements between departments in terms of lead-time standards, created dysfunctional, internal and dynamic complexity through uncertainty in the treatment and discharge process across the care ecosystem.

\section{Interview data}

The interview participants were asked to identify who participates in the care ecosystem and why? Mostly skill-based actors were identified such as doctors, nurses, and physiotherapists. However, the $\mathrm{CH} 1$ participants also viewed the funding groups as customers as they paid for the service. This contradicts earlier research which assumes a common focus to deliver a value proposition for patients (Vargo and Lusch, 2017; Randall et al, 2010; Carroll et al, 2007) and confirms a duality of focus in public services which adds to detailed complexity.

Secondly participants were asked to identify what patients wanted from the community hospital service provision. A number of attributes were identified. These were:

- being treated with dignity and privacy $(\mathrm{AH} 1 / \mathrm{CH} 1)$, 
- timely access to assessment and treatments (AH1/CH1/AH2/CH2),

- continuity of care (AH2/CH2),

- cleanliness and a safe environment (AH1/CH1/AH2/CH2),

- information and communication (AH1/CH1/AH2/CH2/C1),

- to be reassured about the implications of going home $(\mathrm{CH} 1 / \mathrm{CH} 2 / \mathrm{C} 1 / \mathrm{C} 2)$,

- minimum waiting times, to go home as early as possible $(\mathrm{CH} 1 / \mathrm{C} 1)$,

- empowerment and choice (AH2/CH2/C1/C2),

- $\operatorname{good}$ food (CH1),

The combination of these factors became the value cocreation proposition for service improvement.

Interviewee participants from the home care and social services setting (C1/C2) highlighted that resources existed but were not being used for the direct referral of patients to their home from the acute hospital. The resources available but not fully utilised were provided by occupational therapists (OT). The participants proposed supportive stepdown services provided by occupational therapies in the home or on behalf of social services. These services represented co-created value and aided safe patient recovery by directly discharging suitable patients from the acute hospital setting. The participants provided copies of the 'awareness raising' documentation to support those undertaking discharge at the acute hospitals. The failure to utilise the arranged Local Authority OT capacity by the acute hospitals demonstrated issues with externally generated initiatives and the uncertainty which can occur across organisational boundaries. Reflecting both externally generated and dynamic complexity. One participant highlighted their concern stating 'It's as though this service [local authority provision] has been blocked. I am sure we could support more patients than are currently referred' $(\mathrm{C} 1)$. Participants from the acute setting were either unaware of the local authority 'OT service' or were aware but concerned about the robustness of the service as one respondent from the acute hospital expressed, 'I have heard about a service supplied by OTs for patients in their own homes. It is not clear how it works, ...I know that the service in the community hospital works' (AH1). Additionally, care professionals needed to be assured the service would match or exceed previous arrangements to minimise risk.

When participants described their roles in the care ecosystem it became apparent discharge planning started from first principles in the community hospital because professional standards require that an individual is professionally liable for patient diagnosis and treatment $(\mathrm{CH} 1)$. Each medical professional individually reviews the preceding assessment regardless of the prior work undertaken or the complexity of the patient condition. The exchange of services between actors, (from one setting to another i.e. patients treatments are reassessed at every handover between professionals which could be acute hospitals to community hospitals, but equally could be at handover between shifts), was constrained by institutional arrangements. Additionally, it was reported that activities already undertaken were repeated as personal surety $(\mathrm{CH} 1 / \mathrm{CH} 2)$. The duplication of effort and delays reflected necessary complexity due to professional standards which the care ecosystem has to absorb.

The service provided by nurses for patients in the community hospital included ensuring a meal was eaten before discharge. One participant stated, 'we prefer to ensure patients 
are discharged after lunch so that they have a good meal' (CH1). Another participant told of an instance where a patient was to be discharged to a home in a 'garage' $(\mathrm{CH} 1)$. The participant added that they had been advised the patient had been admitted from the same location as the patient was returning, 'it did not seem right that the patients should be discharged there.' (CH1). The psychological response of staff to the frailty of patients being discharged impacted the timing of new patients being admitted. This activity supported the exchange of service and co-creation of value with social services related to assurance of the patient's wellbeing before handover to the next stage in the supply chain. An unintended impact of the actor's psychological response was on the timing of transfer of new patients and thus flows of patients from the acute hospital to the community hospital. The lack of standards for well-being within the handover process meant that internal and dynamic complexities were apparent.

In our case study all patients are clinically assessed and automatically referred to a physiotherapist in the community hospital but not all are referred to an occupational therapist $(\mathrm{CH} 1 / \mathrm{CH} 2)$. Medical team ward rounds in the community hospital were alternate days $(\mathrm{CH} 1 / \mathrm{CH} 2)$. Concern was expressed about the team not addressing treatment of rehabilitation patients at the admission stage $(\mathrm{CH} 1 / \mathrm{CH} 2)$. Nurses considered that patient co-morbidities (bio-medical detailed complexity) and the challenges these involve could be highlighted at the medical team ward round which would require involvement of other professionals. Participants noted 'OTs were not part of the ward round' $(\mathrm{CH} 1)$; 'Referrals [to OTs] are often too early or too late to be effective' $(\mathrm{CH} 2)$; 'patients are transferred [from acute hospital] who are not on the transfer list' $(\mathrm{CH} 2)$. The lack of integration and the dynamic uncertainty created across the care ecosystem meant that value co-created earlier in process was, in part, dissipated as ward round teams were not cognizant of patient illness complexity and the need for other actors to be involved in the service exchange. This led to duplication, delays and internally generated dysfunctional complexity.

From the analysis of the data collected and interviews conducted through the SDL lens several complexity issues were identified in the care ecosystem (see table 4). Failure to use newly introduced occupational therapy capacity and realise its value creation highlighted a lack of integration of resources (bypass patient stay in a community hospital). Institutional management practices regarding new service introduction hindered integration of resources being funded by care commissioners leading to the manifestation of uncertainty about the use and availability of the therapy capacity across nodes (dynamic and external complexity). Risk minimisation through maintaining treatment within the confines of the community hospital highlighted complexity that was viewed as necessary. The institutional approach to minimising risk, for patients and professionals, had led to wards visits being viewed as individual specialist time slots with no overlap. This derived dysfunctional complexity, amongst other types of complexity, as opportunities to improve efficiency and co-create value were lost. Failure to align and integrate resources also led to delays and uncertainty in other services as well as the delivery of value. These issues manifested internal, dynamic and dysfunctional complexities. The recurring issue with the co-creation of value was linked to the institutional arrangements to minimise risk, patient and professional, within the care ecosystem. This was identified in patient discharge and transfer of care delays which manifested in dysfunctional, necessary, external and dynamic complexities. 


\begin{tabular}{|c|c|c|c|}
\hline $\begin{array}{l}\text { SDL } \\
\text { foundational } \\
\text { premises } \\
\text { required to co- } \\
\text { create value }\end{array}$ & $\begin{array}{l}\text { Issues limiting } \\
\text { co-creation of } \\
\text { value }\end{array}$ & $\begin{array}{l}\text { Example of } \\
\text { failure }\end{array}$ & $\begin{array}{l}\text { Complexity } \\
\text { manifested as } \\
\text { experienced by } \\
\text { care } \\
\text { professionals }\end{array}$ \\
\hline $\begin{array}{l}\text { Service } \\
\text { exchange }\end{array}$ & $\begin{array}{l}\text { Service } \\
\text { exchange } \\
\text { constrained and } \\
\text { a lack of } \\
\text { integration of } \\
\text { resources due } \\
\text { to institutional } \\
\text { management } \\
\text { practices. }\end{array}$ & $\begin{array}{l}\text { Failure to use } \\
\text { new introduced } \\
\text { occupational } \\
\text { therapy capacity } \\
\text { limiting } \\
\text { efficiency gains }\end{array}$ & $\begin{array}{l}\text { External, dynamic } \\
\text { and necessary } \\
\text { complexity }\end{array}$ \\
\hline $\begin{array}{l}\text { Value is } \\
\text { created by } \\
\text { multiple actors }\end{array}$ & $\begin{array}{l}\text { Actors unable to } \\
\text { develop co- } \\
\text { create value } \\
\text { together due to } \\
\text { different } \\
\text { institutional } \\
\text { arrangements }\end{array}$ & $\begin{array}{l}\text { Non-aligned } \\
\text { ward visits due } \\
\text { to uncoordinated } \\
\text { discharge } \\
\text { planning across } \\
\text { different settings }\end{array}$ & $\begin{array}{l}\text { Detail, internal } \\
\text { and dysfunctional } \\
\text { complexity }\end{array}$ \\
\hline $\begin{array}{l}\text { Integration of } \\
\text { resources }\end{array}$ & $\begin{array}{l}\text { Resource } \\
\text { integration was } \\
\text { limited leading } \\
\text { to delays in } \\
\text { service } \\
\text { exchange. }\end{array}$ & $\begin{array}{l}\text { Support services } \\
\text { such as scans } \\
\text { suffered from } \\
\text { lead-time } \\
\text { variability } \\
\text { causing delays in } \\
\text { subsequent } \\
\text { activities }\end{array}$ & $\begin{array}{l}\text { Internal, dynamic } \\
\text { and dysfunctional } \\
\text { complexity }\end{array}$ \\
\hline $\begin{array}{l}\text { Institutional } \\
\text { arrangements }\end{array}$ & $\begin{array}{l}\text { (1) Institutional } \\
\text { arrangements } \\
\text { to limit } \\
\text { professional risk } \\
\text { and slowing } \\
\text { service } \\
\text { exchange. } \\
\text { (2) Delays in } \\
\text { service } \\
\text { exchange } \\
\text { created by } \\
\text { different } \\
\text { institutional } \\
\text { arrangements } \\
\text { across the care } \\
\text { ecosystem. }\end{array}$ & $\begin{array}{l}\text { (1) Timing of } \\
\text { Dr's ward round } \\
\text { and } \\
\text { reassessment of } \\
\text { patients by } \\
\text { Occupational } \\
\text { Therapists } \\
\text { slowed } \\
\text { effectiveness and } \\
\text { efficiency of } \\
\text { service exchange } \\
\text { (2) Delayed } \\
\text { transfer of care }\end{array}$ & $\begin{array}{l}\text { (1) Dysfunctional } \\
\text { and necessary } \\
\text { complexity } \\
\text { (2) External and } \\
\text { dynamic } \\
\text { complexity }\end{array}$ \\
\hline
\end{tabular}

Table 4: Complexity in the care ecosystem 


\section{Responses to complexity}

The output of the semi-structured interviews, descriptive statistics and secondary data was presented to all interview participants for validation and reflection. Having identified the issues, the participants developed and implemented actions to address the problems. The demand analysis was challenged by the community hospital participants (CH1) and a separate local exercise conducted by the local management ensued $(\mathrm{CH} 2)$. The volumes of patients being referred to the community hospital were much less than expected by those actors in the case study. The outcome of the local exercise and further discussions was a new understanding about the psychological impact on staff of those patients who remained in the community hospital. The long duration of stay in hospital seemingly created an impression of no capacity and did not reflect the improvements in discharge rates for those patients who were discharged safely and promptly from the community hospital $(\mathrm{CH} 1 / \mathrm{CH} 2)$. Delays in transfer of patients across the care ecosystem reflect delays in the exchange of services. Institutional arrangements between each stage of the care ecosystem were not aligned to support seamless and timely integration of services. A suggestion made and subsequently adopted through a strategic implementation plan was streaming patients to allow a clear sense of progress which was within the actor's span of control $(\mathrm{AH} 1 / \mathrm{CH} 1 / \mathrm{CH} 2)$ reducing both the external and dynamic complexities.

An improvement to remove a step from the supply chain through use of the home-based therapy service was made $(\mathrm{AH} 1 / \mathrm{C} 1)$ leading to a reduction in internal and dynamic complexity. The re-introduction of the home based services to improve the service for a selected group of patients entailed not having to be admitted to the community hospital but rather receive treatment at home. However, it transpired that making such a service available was not sufficient. Care professionals needed to be assured the service, that is managed through institutional arrangements would exceed what was already in place and would operate on the basis of minimising risk through personal ownership of service exchanges (AH1/AH2).

AH1 acknowledged and agreed patients from the acute setting (upstream) could have provided input into the discharge plan of the community hospital as part of the handover documentation for the patient and was included in the improvement plan to reduce dysfunctional complexity. Allowing the patient to co-create value was viewed as a way of improving the service exchange through integrating the resources and reducing complexity.

\subsection{Discussion}

SDL as a research lens provided a basis for analysing and comprehending the challenges and issues faced by healthcare professionals in addressing growing complexity in the care ecosystem. Through examining how services are exchanged in the co-creation of value the case study revealed several aspects of complexity. The six complexity types developed through supply chain based research were shown to be relevant to the care ecosystem. Demonstrating the opportunity for care professionals to identify and manage dysfunctional complexity as it currently exists or emerges. The case study also demonstrated some approaches which can be deployed to minimise the negative impact of complexity though each example is context specific. We acknowledge that the findings distilled from a single case study require additional research to generate results which are generalisable for healthcare professionals. 
Through the application of the SDL the case study revealed the significant role of institutional arrangements in the operation of care ecosystems. Care professionals were required to conduct the final assessment, between departments, on a patient to minimise safety issues was a common occurrence across the care ecosystem. This reflects the institutional arrangement that senior medical professionals must always approve the closure of a patient's treatment before moving onto the next stage of the patient pathway. This decoupling and recoupling between stages creates complexity which we label as "institutional". We define institutional complexity in care ecosystems as "complexity that constrains service exchanges from achieving a higher level of efficiency and effectiveness at the expense of potential patient safety issues".

The dual nature of institutional complexity mirrors the concepts of necessary and dysfunctional complexity (Aitken et al, 2016). Constraining the service exchange through ensuring that professionals are responsible and accountable for patients is a necessary complexity which currently operates in the care ecosystem. Therefore, producing a tension for actors between the need to preserve professional boundaries while supporting service exchanges based on collaboration. Within the community hospital necessary complexity was absorbed through improving the use and accuracy of protocols to minimise risk centred on the institutional arrangements of professional accountability. Through collaboration within the boundaries of the community hospital the actors were able to develop knowledge and design solutions to minimise value loss in the service exchange when discharging patients. Developing greater levels of assurance on the quality and rigour of the home-based occupational service supported the integration and improved service exchange for patients, reducing the perceived professional risk between the community hospital and step-down services.

As with all organisations any activities that can reduce dysfunctional complexity to improve efficiency and effectiveness in service exchanges should be encouraged. Different work practices created information flow difficulties between actors, due to institutional arrangements such as ward round times which were not synchronised, leading to dysfunctional complexity. Developing a perspective of an integrated service (as shown in the realignment of ward rounds) within the care ecosystem supported actors in the co-creation of value which reduced dysfunctional complexity and waste. Nonalignment of resources created delays in service exchange leading to waste. From an efficiency perspective dysfunctional complexity caused by interruptions and delays to patients flowing through the care ecosystem should be minimised. However, the assurance of patient well-being, due to increased levels of frailty, was found to cause unanticipated delays which the care ecosystem had to absorb. At a care ecosystem level maximising co-creation of value was countered by ensuring that risk associated with patient safety and well-being was prioritised.

Institutional complexity was found in the case study to be both necessary and dysfunctional in nature. The community hospital deployed both reductionist and absorptive approaches to address the complexities that existed and emerged in the ecosystem (see figure 4). Professionals in addressing these complexities migrated from a fragmented approach, within the community hospital boundaries, to supporting patients through the development of integrated resources and improved exchange of services. 
Complexity management approaches

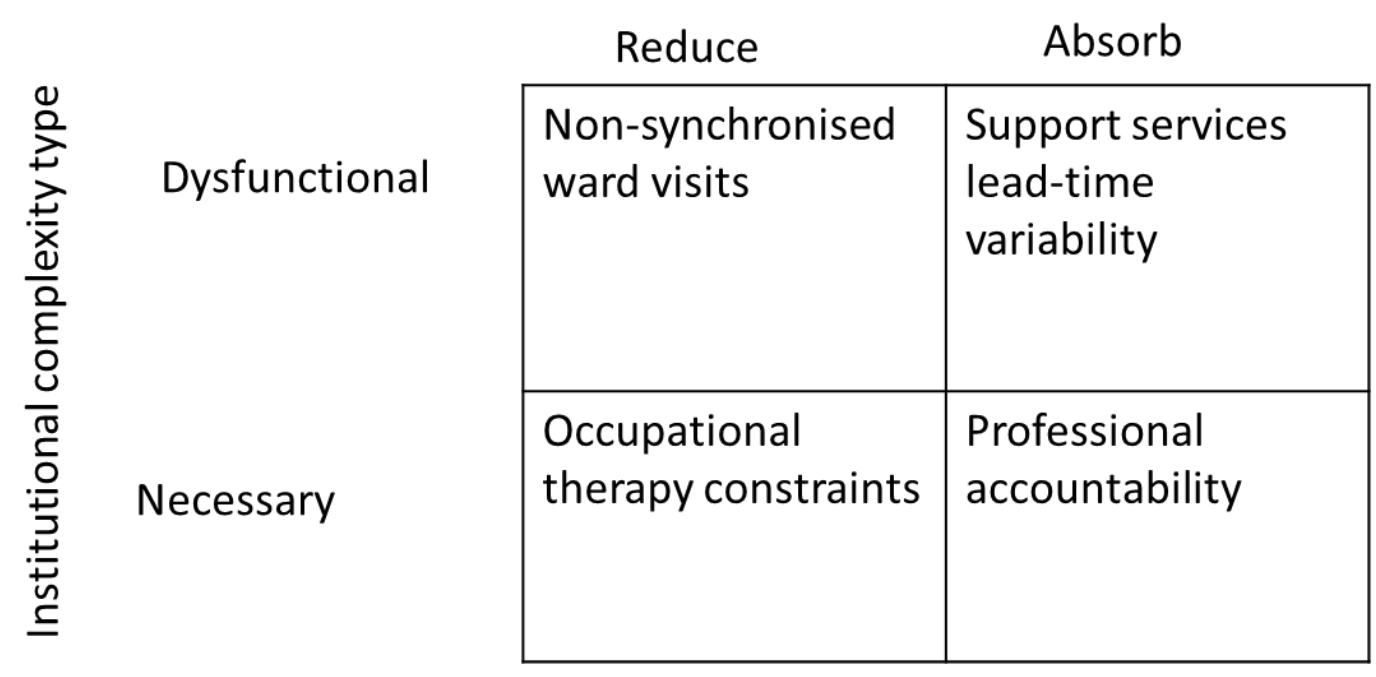

Figure 4: Institutional complexity types \& complexity management approaches

Figure 4 provides with another level of granularity into the institutional complexity which manifests itself within care ecosystems. Demonstrating the strategies which can be introduced/applied to reduce or absorb complexity.

\subsection{Implications for theory and practice}

The findings from this research provide some empirical support for the application of the six supply chain derived complexity types within care ecosystems. Historically complexity has been studied from the perspective of negativity with a focus on the development of approaches to identify and minimise its dysfunctional consequences (Serdarasan, 2012; Bozarth et al, 2009). Recently the literature has begun to outline the positive aspects of complexity through the development of competitive advantages through increased service and product offerings (Turner et al, 2018; Aitken et al, 2016). Through highlighting another level of granularity this research has found evidence of this duality of complexity in the care ecosystem providing the opportunity for healthcare professionals to gain insights and guidance, from supply chain management literature, for possible responses to managing complexity.

From a research perspective, the institutional complexity identified through the case study provides another dimension to the body of complexity knowledge. The role of institutional arrangements in addressing complexity has not, to the knowledge of the authors, been discussed in the supply chain management literature. Considering the importance of institutional complexity and its potential research application for the wider academic community two questions arise;

1. The SDL framework has revealed the importance of institutional arrangements within care ecosystems adding another layer of complexity for care professionals to manage. Due to the significant role of institutional complexity in care ecosystems professionals must be considerate of the actions to be taken to manage the negative consequences of complexity. This requires care professionals to develop a balanced approach between reducing complexity that impacts on the efficiency and effectiveness of service exchange, while absorbing the need for necessary institutional arrangements which minimise risk. 
The dualistic nature to addressing care ecosystem complexity requires further research to determine if there are common approaches that care professionals can deploy. For example, developing protocols across departments which simplify processes, minimising detail derived complexity, while ensuring the needs of professionals to manage risk are met. If patterns of "good practice" can be identified these could be shared across other areas or sectors governed by institutional arrangements which minimise professional risk.

2. The case study highlighted the impact of externally generated complexity when commissioners attempted to alter the flow of patients from acute hospitals through the provision of home occupational therapy treatment. The initiated changes failed to address the concerns of care professionals in terms of risk. This example highlights the challenges faced by policy makers when trying to influence and improve patient treatment. Future research should investigate the approaches and mechanisms that can be deployed to support policy changes when faced with institutional arrangement complexity. Is there a sequence of addressing complexity in care ecosystems? Should institutional arrangement complexity be the first stage of action or can changes across several types of complexity occur concurrently?

\subsection{Conclusion}

Management of complexity in care ecosystems requires professionals to be considerate of institutional arrangements. Through recognising how complexity manifests itself, as experienced by care ecosystem professionals, institutional complexity was identified. This complexity highlighted competing interests of actors, due to institutional arrangements, which can hinder the co-creation of value for services designed to deliver the care ecosystem's value proposition. This necessitates the development of a balanced approach between reducing complexity while absorbing institutional arrangements which minimise risk. This knowledge provides support for professionals when addressing the consequences of increasing levels of complexity.

Insights from supply chain complexity research can support care professionals in comprehending the characteristics of the complexity within the care ecosystem, as well as understanding consequences of its impact on its operation. Recognizing the type of complexity proffers the opportunity to develop and select an appropriate response to support value co-creation and drive down waste (and thus improve service delivery). Through our research we have begun to identify the complexities faced by care professionals as well as approaches to reducing the negative consequences of increasing levels of complexity. Addressing in part the challenge that complexity is an abstract concept with limited relevance and fit for what care professionals need (Greenhalgh et al, 2018).

This study is the first, to the knowledge of the authors, to employ SDL in the analysis of complexity in a public service domain. Drawing on the supply chain complexity literature, the paper has developed a framework which can assist care professionals in the management of increasing levels of complexity and in turn enable professionals to evaluate complexity dimensions for service effectiveness. While single case studies are valid to study emergent themes, this work would benefit from further testing across a broader spectrum of care ecosystems to further validate the institutional complexity framework proffered in this paper. In particular, future research should focus on the role and types of institutional arrangements which can either hinder or support the ability of an ecosystem to adapt to evolving complexity. 


\section{References}

Aitken, J. Bozarth, C. and Garn, W. (2016). "To eliminate or absorb supply chain complexity: a conceptual model and case study", Supply Chain Management: An International Journal, Vol. 21, No. 6, pp 759-774

Aronsson, H., M. Abrahamsson, and Spens,K., (2011). "Developing lean and agile health care supply chains," Supply Chain Management: an International Journal, Vol. 16, No. 3, pp 176-183.

Bode, C. and Wagner, S. (2015), "Structural drivers of upstream supply chain complexity and the frequency of supply chain disruption's", Journal of Operations Management, Vol. 36, pp. 215-228.

Bozarth, C., Warsing, D., Flynn, B. and Flynn, J. (2009), "The impact of supply chain complexity on manufacturing plant performance", Journal of Operations Management, Vol.27, pp 78-93.

Carroll, R. Cnossen, R. Schnell, M. and Simons, D (2007): “Continua: An interoperable personal healthcare ecosystem”. IEEE Pervasive Computer. Vol. 6, No.4, pp. 90-94

Chakraborty, S. and Dobrzykowski, D. (2013), "Supply chain practices for complexity in healthcare: A service-dominant logic view", IUP Journal of Supply Chain Management, Vol.10, No. 3, pp.53-75.

Childerhouse, P., Towill, D.R. (2004), "Reducing uncertainty in European supply chains", Journal of Manufacturing Technology Management, Vol. 15 No. 7, pp. 585598.

Choi, T.Y., Dooley, K.J., Rungtusanatham, M.(2001), "Supply networks and Complex adaptive systems: control versus emergence", Journal of Operations Management Vol.19 No.3, pp. 351-366

Churruca, K., Pomare, C., Ellis, L.A., Long, J.C. and Braithwaite, J., (2019). "The influence of complexity: a bibliometric analysis of complexity science in healthcare". BMJ open, Vol. 9, No. 3, pe027308.

Cohn, S., M. Clinch, C. Bunn, and Stronge.P., (2013). "Entangled Complexity: Why complex interventions are just not complicated enough." Journal of Health Services Research and Policy Vol. 18, No. 1., pp 40-43.

Curtis, S. and Riva, M., (2010), "Health geographies II: complexity and health care systems and policy", Progress in Human Geography, Vol. 34, No. 4, pp.513-520.

Dessers, E. and Mohr, B.J., (2018), "Values and challenges in a care ecosystem design approach". International Journal of Integrated Care Vol. 18, pp1-2

Eisenhardt, K. (1989), "Building theories from Case Study Research”. Academy of Management Review Vol. 14, pp 532-550.

Esain, A. (2011), "A Socio-Technical Systems perspective of the operational delivery of Secondary Care in the NHS". PhD Thesis, Cardiff University.

Fraser, S.W. and Greenhalgh, T., (2001), "Coping with complexity: educating for capability". BMJ, Vol. 323, No. 7316, pp.799-803.

Frizelle, G.,and Woodcock, E.(1995), "Measuring complexity as an aid to developing operational strategy", International Journal of Operations \& Production Management, Vol. 15 No. 5, pp. 26-39. 
Frow, P. McColl-Kennedy, J. Hilton, T. Davidson, A. Payne, a. and Brozovic, D. (2014), "Value propositions: A service ecosystem perspective". Marketing Theory, Vol. 14, No. 3, pp. 327-351.

Gehmlich, V. (2008). "Opportunites of supply chain management in healthcare". In Hubner, U. and Elmhorst, M. (eds), E-business in Healthcare: From E-procurement to Supply chain management, Springer-Verlag, London.

Gerschberger, M., Engelhardt-Nowitzki, C., Kummer, S., and Staberhofer, F.(2012), “A model to determine complexity in supply networks", Journal of Manufacturing Technology Management, Vol. 23 No. 8, pp. 1015-1037.

Greenhalgh, T. (2009), "Complexity theory and family medicine: A new symbiosis", Swiss Journal of Family Medicine, Vol. 331, No. 1

Greenhalgh, T., Humphrey, C., Hughes, J., Macfarlane, F., Butler, C. and Pawson, R.A.Y., (2009), "How do you modernize a health service? A realist evaluation of whole-scale transformation in London". The Milbank Quarterly, Vol. 87, No.2, pp.391-416.

Greenhalgh, T. and Papoutsi, C. (2018), "Studying complexity in health services research: desperately seeking an overdue paradigm shift". BMC Medicine, Vol. 16, No. 95, pp $1-6$.

Greenhalgh, T., Wherton, J., Papoutsi, C., Lynch, J., Hughes, G., Hinder, S., Procter, R. and Shaw, S., (2018), "Analysing the role of complexity in explaining the fortunes of technology programmes: empirical application of the NASSS framework". BMC Medicine, Vol. 16, No. 1, pp.1-15.

Grudniewicz, A., Tenbensel, T., Evans, J.M., Gray, C.S., Baker, G.R. and Wodchis, W.P., (2018), "Complexity-compatible'policy for integrated care? Lessons from the implementation of Ontario's Health Links". Social Science \& Medicine, Vol. 198, pp.95-102.

Gummesson, E., Doyle, G., Storlazzi, A., Annarumma, C., Favretto, G., Tommasetti, A. and Vesci, M., (2018), "Health Myths and Service-Dominant Logic". in The Myths of Health Care, pp. 231-251.. Springer, Cham.

Gummesson, E. Mele, C. and Polese, F. (2019), "Complexity and viability in service ecosystems," Marketing Theory, Vol. 19, No. 1, pp.3 -7.

Heaney, D., Black, C., O'Donnell, C.A., Stark, C. and Van Teijlingen, E., (2006), "Community hospitals-the place of local service provision in a modernising NHS: an integrative thematic literature review”, BMC public health, Vol. 6, No. 1, p.309.

Heinonen, K., Strandvik, T. and Voima, P., (2013). "Customer dominant value formation in service". European Business Review, Vol. 25, No. 2, pp.104-123.

Huijsman, R., Vissers, J.M.H., Camps, T., Diederen, P., Hofstede, G.J. and Vos, B., (2004). "Supply chain management in health care: State of the art and potential". The emerging world of chains and networks: bridging theory and practice, pp.147-167.

Jacobides, M.G., Cennamo, C. and Gawer, A., (2018), "Towards a theory of ecosystems". Strategic Management Journal, Vol. 39, No. 8, pp.2255-2276. 
Joiner, K.; Lusch,, R., (2016), "Evolving to a Service-Dominant Logic for Health". Australian. Health Review., Vol. 3, pp. 25-33.

Koskela-Huotari, K. and Vargo, S.L., (2016). "Institutions as resource context". Journal of Service Theory and Practice, Vol. 26, No. 2, pp.163-178.

Lambert, D. and Sebastián J. (2006), "Cross Functional Business Processes for the Implementation of Service-Dominant Logic", in The Service Dominant Logic of Marketing: Dialogue, Debate, and Directions, Robert F. Lusch and Stephen L. Vargo, eds., Armonk, NY: M. E. Sharpe, pp. 150-165.

Liberati, E.G., Gorli, M. and Scaratti, G., (2016), "Invisible walls within multidisciplinary teams: disciplinary boundaries and their effects on integrated care". Social Science and Medicine, Vol. 150, pp.31-39.

Lodge, A. and Bamford D. (2008), "New development: Using lean techniques to reduce radiology waiting times". Public Money and Management Vol. 28, No. 1, pp. 49-52.

Lusch, R.F., (2011). "Reframing supply chain management: a service-dominant logic perspective". Journal of Supply Chain Management, Vol. 47, No. 1, pp.14-18

Lusch, R.F. and Vargo, S.L., (2014). Service-dominant logic: Premises, perspectives, possibilities. Cambridge University Press

Manju, L.and Sahin, F. (2011), "A model of supply chain and supply chain decisionmaking complexity", International Journal of Physical Distribution and Logistics Management, Vol. 42 No. 5, pp. 511-549.

Mazzocato, P., Thor, J., Bäckman, U., Brommels, M., Carlsson, J., Jonsson, F., Hagmar, M. and Savage, C., (2014), "Complexity complicates lean: lessons from seven emergency services". Journal of Health Organization and Management, Vol. 28, No. 2, pp.266-288.

McColl-Kennedy, J.R., Vargo, S.L., Dagger, T.S., Sweeney, J.C. and Kasteren, Y.V., (2012). "Health care customer value cocreation practice styles". Journal of Service Research, 15(4), pp.370-389.

Meijboom, B., Schmidt-Bakx, S. and Westert, G., (2011). "Supply chain management practices for improving patient-oriented care". Supply Chain Management: an International Journal, Vol. 16, No. 3, pp.166-175.

Meredith, J. (1998), "Building operations management theory through case and field research". Journal of Operations Management, Vol. 16 No. 4, pp. 441-454.

Ng, I., Parry, G., Smith, L., Maull, R. and Briscoe, G., (2012), "Transitioning from a goods-dominant to a service-dominant logic". Journal of Service Management, Vol. 23, No. 3. pp $416-439$

.Nilsson, F. and Darley, V., (2006). "On complex adaptive systems and agent-based modelling for improving decision-making in manufacturing and logistics settings: Experiences from a packaging company". International Journal of Operations \& Production Management, Vol. 26, No. 12, pp.1351-1373.

Orton, L., Ponsford, R., Egan, M., Halliday, E., Whitehead, M. and Popay, J., (2019), "Capturing complexity in the evaluation of a major area-based initiative in community empowerment: what can a multi-site, multi team, ethnographic approach offer?". Anthropology and Medicine, Vol. 26, No. 1, pp.48-64. 
Osborne, S.P., Radnor, Z. and Nasi, G., (2013). "A new theory for public service management? Toward a (public) service-dominant approach". The American Review of Public Administration, Vol. 43, No. 2, pp.135-158.

Osborne, S.P., Radnor, Z. and Strokosch, K., (2016). "Co-production and the co-creation of value in public services: a suitable case for treatment?". Public Management Review, Vol. 18, No. 5, pp.639-653.

Paley, J (2010), “The appropriation of complexity theory in health care “,Journal of Health Services Research \& Policy", Vol. 15, No, 1: pp. 59-61

Pathak, S., Day, J. M., Nair, A., Sawaya, W., Kristal, M. (2007). "Complexity and Adaptivity in Supply Networks: Building Supply Network Theory Using a Complex Adaptive Systems Perspective”. Decision Sciences Journal, Vol. 38, No. 4., pp. 547580

Pitchforth, E., Nolte, E., Corbett, J., Miani, C., Winpenny, E., Van Teijlingen, E., Elmore, N., King, S., Ball, S., Miler, J. and Ling, T., (2017), "Community hospitals and their services in the NHS: identifying transferable learning from international developments-scoping review, systematic review, country reports and case studies". Health Services and Delivery Research, Vol. 5, No. 9.

Quist, J. and Fransson, M., (2014). Collaborative Service Innovation in the Public Sector. In Framing Innovation in Public Service Sectors. Routledge.UK

Radnor, Z.J., Holweg, M. and Waring, J., (2012), "Lean in healthcare: the unfilled promise?”, Social Science and Medicine, Vol. 74, No. 3, pp.364-371.

Radnor, Z., Osborne, S.P., Kinder, T. and Mutton, J., (2014). “Operationalizing coproduction in public services delivery: The contribution of service blueprinting". Public Management Review, Vol. 16, No.3, pp.402-423.

Randall, W.S., Pohlen, T.L. and Hanna, J.B., (2010). "Evolving a theory of performancebased logistics using insights from service dominant logic". Journal of Business Logistics, Vol. 31, No. 2, pp.35-61.

Schiffling, S., Hannibal, C., Tickle, M. and Fan, Y., (2020), "The implications of complexity for humanitarian logistics: a complex adaptive systems perspective". Annals of Operations Research, pp.1-32.

Serdarasan, S. (2012), “A review of supply chain complexity driver's", Computers \& Industrial Engineering, Vol. 66, pp. 533-540.

Sturmberg, J.P., Martin, C.M. and Katerndahl, D.A., (2014). "Systems and complexity thinking in the general practice literature: an integrative, historical narrative review". The Annals of Family Medicine, Vol. 12, No. 1, pp.66-74.

Strange, W.C., (2009). "Agglomeration research in the age of disaggregation". Canadian Journal of Economic, Vol. 42, No. 1, pp.1-27.

Thompson, D.S., Fazio, X., Kustra, E., Patrick, L. and Stanley, D., (2016). "Scoping review of complexity theory in health services research". BMC Health Services Research, Vol. 16, No. 1, pp 87-103.

Tukamuhabwa, B.R., Stevenson, M., Busby, J. and Zorzini, M.,( 2015). Supply chain resilience: definition, review and theoretical foundations for further study. International Journal of Production Research, Vol. 53, No. 18, pp.5592-5623. 
Turner, N. Aitken, J. and Bozarth, C., (2018). "A framework for understanding managerial responses to supply chain complexity", International Journal of Operations \& Production Management, Vol. 38, No. 6, pp.1433-1466

Vachon, S. and Klassen, R.(2002), "An exploratory investigation of the effects of supply chain complexity on delivery performance", IEE Transactions on Engineering Management, Vol. 49 No. 3. pp. 218-230.

Vargo, S.L. and Lusch, R.F., (2008). "Service-dominant logic: continuing the evolution". Journal of the Academy of Marketing Science, Vol. 36, No. 1, pp.1-10.

Vargo, S.L. and Lusch, R.F., (2016), "Institutions and axioms: an extension and update of service-dominant logic". Journal of the Academy of Marketing Science, Vol. 44, No. 1, pp.5-23.

Vargo, S.L. and Lusch, R.F., (2017), "Service-dominant logic 2025". International Journal of Research in Marketing, Vol. 34, No. 1, pp.46-67.

Vural, C. (2017). "Service-dominant logic and supply chain management: A systematic literature review", Journal of Business \& Industrial Marketing, Vol. 32, No. 8, pp. 1109-1124.

Walley, P. (2013), "Does the public sector need a more demand-driven approach to capacity management?" Production Planning \& Control, Vol. 24, No. 10, pp 870-899

Wallis, S, (2008)"Emerging order in CAS theory: mapping some perspectives", Kybernetes, Vol. 37 No. 7, pp. 1016-1029

Westrup, U., (2018). "The potential of service-dominant logic as a tool for developing public sector services: A study of a Swedish case". International Journal of Quality and Service Sciences, Vol. 10, No. 1, pp.36-48.

Williams, S. (2017). Improving Healthcare Operations: The application of Lean, Agile and Leagility in Care Pathway Design, Palgrave, Sweden.

Wilding, R. (1998), "The supply chain complexity triangle: Uncertainty generation in the supply chain", International Journal of Physical Distribution and Logistics Management, Vol. 28 No. 8, pp. 599-616

Yin, R. K., (2014). Case Study Research: Design and Methods. 5th London: Sage. 
Appendix A - Semi Structures Interview Questions and Coding

\section{Definition of care ecosystem given to interviewees}

\section{Actors involved in the care ecosystem}

Q. 1. Who participates in the care ecosystem and why?

Q. 2. What do you understand to be the wants and needs of the patients in the care ecosystem?

\section{Integrations of Resources}

Q.3. Describe your role in the care ecosystem? (from engaging with the patient to handover/discharge)

Q.4. What works well and why in the care ecosystem and what aspects could be improved?

\section{Exchange of Services}

Q.5. How does your role integrate or otherwise with the other actors in the care ecosystem?

Q.6. What works well and why and what could be improved?

\section{Institutional Arrangements}

Q. 7. How do the procedural arrangements work between organisations, within organisations and within wards?

Q. 8. What would you suggest could be different and why?

Q.9. Are there any other comments about the care ecosystem which you would like to share?

Interview Coding (Sources of complexity as determined by literature)

Internally complexity can be generated by quality issues, failures to conform to standards, diverse IT systems, poor process controls and organisational structures Externally issues across organisational boundaries such as customer demand variances or unclear specification of requirements generate complexity. The fragmented nature of care ecosystems and the poor levels of coordination between functional and specialist silos also creates complexity.

Detailed - patients and their range of illnesses, medical suppliers, multi-care agencies and process interactions

Dynamic uncertainty as a major element of dynamic complexity e.g. small change in demand can be magnified across a system leading to significant changes elsewhere in the system. Change in one component can provoke unplanned changes throughout the system.

Necessary complexity - offering higher levels of support across several specialist domains to improve service, older patients, more serious illness, multiple routes through the supply chain to address different levels of need. SDL e.g. value-in-use, customer cocreation

Dysfunctional complexity - too great a variety of service offering causing longer waiting times, larger numbers queuing for services, reductions in capacity due to greater levels of specialisation.

Other complexity attributes which could represent complexity as yet undefined. 